\title{
Sense of Coherence: A Distinct Perspective on Financial WELL-BEING
}

\author{
Antoni Barnard \\ Department of Industrial \& Organisational Psychology, University of South Africa
}

Accepted: September 2016

\begin{abstract}
With the ongoing financial challenges being faced in the economic environment, research exploring financial and psychological well-being is of significant value because employees' socio-economic behaviour affects productivity. Research emphasises mainly the effect of income level on psychological well-being, and its orientation to psychological well-being is narrowly derived from a focus on subjective well-being constructs. This study addresses the research gap by exploring the relationship dynamics between sense of coherence, income level and financial well-being. Secondary data were obtained from a cross-sectional online employee-wellness survey ( $n=7$ 185). The sample distribution included 66 per cent females and 34 per cent males from various age groups, with 46 per cent of the sample comprising single-household earners and 54 per cent sharing household income. Analysis of variance was conducted to examine the relationship dynamics between sense of coherence, level of income and financial well-being. Demographic variables that formed part of the survey results were included in the analysis. The relationships between sense of coherence and identified significant income level, financial well-being and demographic effects were further explored in Bonferroni multiple comparisons of means test and cross reference frequency tables that included Pearson's chi-square and/or Cochran-Armitage trend tests. Detail results indicate that high-income employees exhibit a significantly stronger sense of coherence than low-income employees, and that, despite level of income, financial wellbeing is nevertheless positively related to sense of coherence. Results indicate important implications for managing a financially healthy workforce. Limitations are discussed and recommendations for future research are highlighted.
\end{abstract}

Key words: employee well-being, salutogenesis, sense of coherence, financial well-being, level of income, work performance

JEL: D14, 19, 69, O5

\section{$1 \quad$ Introduction}

Employee wellness is foundational to productive and profitable organisational functioning, because psychologically well individuals adopt effective and productive work-life strategies (Diener \& Seligman, 2004). Financial well-being, an aspect of employee wellness (Sieberhagen, Pienaar \& Els, 2011), correlates with productivity on the job (Leary, 2009) and spills over to other areas of life with positive effect (Diener \& Seligman, 2004). Conversely, financial distress, and especially over-indebtedness, is a major stressor impacting negatively on work behaviour, productivity and mental health (Bosman, 2007; Brown, Taylor \& Price, 2005; Cox, Hooker, Markwick \& Reilly, 2009; Delafrooz \& Paim, 2011; Fitch, Hamilton, Bassett \& Davey, 2011; O’Neill, Sorhaindo, Xiao \& Garman, 2005; Siahpush, Spittal \& Gopal, 2007; Zurlo, Yoon \& Kim, 2014). The author of the present paper posits that employees' financial distress may furthermore become an organisational burden due to its negative effect on absenteeism and organisational commitment and the encumbrance of having to manage employee loans, garnishee-order administration and the risk of potential criminal behaviour such as theft and fraud. For employers, it is therefore beneficial to manage employees' financial well-being in a proactive manner and arguments such as those of Diener and Seligman (2004) suggest that a psychological perspective could facilitate such a proactive approach.

The large body of research on the "economics of happiness" (see Dolan, Peasgood \& White, 2008) focuses predominantly on the effect of income level (wealth) on psychological well-being and led to the coining (Easterlin, 1947) and reaffirmation (Easterlin, 2001; Easterlin, McVey, 
Switek, Sawangfa \& Zweig, 2010) of the Easterlin Paradox. The Easterlin Paradox holds that happiness is positively related to wealth because people with more wealth are happier than those reporting lower income levels, but that a society does not become happier as its wealth increases. Recent research within and across nations has confirmed that wealthy people report greater wellbeing than people with lower incomes, but has also demonstrated that a rise in income leads to a definite rise in self-reported well-being, irrespective of one's income category (Diener, Tay \& Oishi, 2013; Sacks, Wolfers \& Stevenson, 2012). Further evidence on psychological well-being rising with level of income indicates a rise to reach a ceiling (Dolan et al., 2008; Kahneman \& Deaton, 2010; Wolbring, Keuschnigg \& Negele, 2013). Yet others point to overwhelming research confirming that financial success actually contributes little to happiness (Gardarsdóttir, Dittmar \& Aspinall, 2009). Research exploring the income-psychological well-being relationship has thus produced varied results, indicating a need for continued exploration in this regard.

As opposed to the many studies investigating the relationship between income and psychological well-being, Bell et al. (2014), as well as Burr, Santo and Pushkar (2011), state that only a limited number of studies explore the effect of financial well-being on psychological wellbeing. On the one hand, income has not been universally accepted as fundamental to psychological well-being (Kahneman \& Deaton, 2010) owing to varied research findings, and, on the other, very few studies such as that by Barnard, Peters and Muller (2010) focus on financial well-being in relation to psychological well-being.

Without exception, research exploring income and financial and psychological well-being dynamics apply subjective well-being (SWB) measures as the primary indicator of psychological well-being (see Bell et al., 2014; Berg \& Veenhoven, 2010; Boyce, Brown \& Moore, 2010; Boyce, Wood, Banks, Clark \& Brown, 2013; Burr et al., 2011; Diener, Harter \& Arora, 2010; Diener et al., 2013; Dolan et al., 2008; Easterlin et al., 2010; Gardarsdóttir et al., 2009; Kahneman \& Deaton, 2010; Deaton, 2008; Sacks et al., 2012). The concept of SWB is used to indicate people's cognitive appraisal of their happiness and quality of life (Field \& Buitendach, 2011), and measures of SWB applied in economic psychology mostly assess self-reported life satisfaction, happiness, or negative and positive effects (see Dolan et al., 2008; Layard, Clark \& Senik, 2012).

The psychological study of well-being has, however, through the evolvement of positive psychology as a discipline, broadened to include a variety of multidimensional wellness constructs over and above the SWB constructs mentioned (Coetzee \& Viviers, 2007; Gropp, Geldenhuys \& Visser, 2007). There is a need to extend research to incorporate variables other than SWB in order to build our understanding of financial and psychological well-being dynamics. Salutogenic theory is a unique health-oriented theory about people's sense of coherence (SOC) established by Antonovsky in the field of psychological well-being (Liukkonen et al., 2010). A study by Barnard et al. (2010) first explored the relationship between SOC and financial health $(n=435)$, finding that respondents with a higher SOC exhibited better overall financial health than respondents with a lower SOC. The present study is designed to address the research gaps indicated above in a more comprehensive sample. Before explicating the aim and hypotheses of the study, conceptual clarification is sought in the following literature review.

\section{Literature review}

\subsection{Financial well-being}

Whilst financial wellness is regarded as a complex multidimensional construct (Joo, 2008), it is conceptually based on objective and subjective indicators of financial well-being (Delafrooz \& Paim, 2011; Gerrans, Speelman \& Campitelli, 2014). Objective financial well-being indicators refer to quantifiable and unbiased aspects of an individual's economic position, such as income, actual debt, and savings or assets (Rutherford \& Fox, 2010). Subjective measures of financial well-being, such as perceived ability to meet expenses, satisfaction with one's financial condition, worry about one's debt, and perceived manageability of debt and savings, provide invaluable 
insight with regard to one's financial wellness that is not achieved through objective measures alone (Delafrooz \& Paim, 2011). According to Gerrans et al. (2014), subjective measures may shed light on an individual's level of financial distress or satisfaction. Yin-Fah, Masud, Hamid, \& Paim (2010) take a behavioural perspective, defining financial well-being as the outcome of financial practices, including financial literacy, attitudes to money, and the process according to which financial resources are managed. Similarly Rutherford and Fox (2010) speak about an active financial-health state as demonstrated by a low level of debt, active saving, and planning for retirement, as well as following a spending plan. In the present study, a combination of objective and subjective financial well-being indicators have been incorporated from an existing secondary data set, for example level of income, perceived manageability of debt, and orientation towards retirement and financial planning.

\subsection{Sense of coherence}

The significant influence of SOC on employee health in the work context has been well established (Vogt, Jenny \& Bauer, 2013) and widely explored as reflective of one's psychological well-being and coping ability (Austin \& Cilliers, 2011; Feldt et al., 2011). SOC was originated by Antonovsky (1979) as the fundamental construct in his salutogenic theory. Salutogenic theory is a health-oriented theory about the SOC construct and is based on the notion that people's orientation to the world provides them with the strength and capacity to resist distress and mental ill health in the midst of challenging circumstances (Liukkonen et al., 2010). Salutogenic theory thus focuses on describing SOC as an orientation to life which facilitates coping and thriving in difficult circumstances (Feldt et al., 2011). Whereas well-being constructs such as happiness and SWB denote a reflective perspective of ones well-being, SOC represents a perspective that provides the individual with agency and active control in responding to environmental stressors. Defining SOC as a wellness-protecting orientation to life (Bernabé et al., 2009; Feldt et al., 2011; Gropp et al., 2007) denotes a proactive orientation to sustaining well-being despite circumstance and places the locus of control in the individual. As such, people with a strong SOC choose strategies to manage and affect their circumstances (Muller \& Rothmann, 2009), suggesting that SOC is an instrumental attribute in facilitating one's well-being.

SOC is based on the point of view that life and all its challenges are meaningful to engage with and that one has the ability to comprehend, manage and respond constructively to challenges (Basinska, Andruszkiewicz \& Grabowska, 2011), thereby implying the three SOC subcomponents of comprehensibility, manageability and meaningfulness. Through the cognitive component, comprehensibility, people perceive their environment as structured, unambiguous and explainable. Through meaningfulness (the motivational component), individuals regard their environment, circumstances and life in general as worthwhile to engage in. Coping behaviour is then further facilitated by manageability, the behavioural component, manifesting in self-confidence that one has sufficient resources to manage life's challenges. As such, SOC plays a predominant role in explaining, developing and maintaining psychological well-being and may enhance understanding of behaviour during financially stressful times and the predisposition to fall into financially difficult situations. Using SOC in financial-wellness research extends our knowledge base regarding the relationship between psychological and financial well-being.

\section{Method}

The study explored a secondary data set derived from an online wellness survey with the primary aim of exploring the relationship between SOC, level of income and financial well-being. The study further included an exploration of the potential effect of demographic variables that formed part of the data set, on SOC. In the light of the stated aim, the following hypotheses were formulated:

Hypothesis 1: There is a positive and statistically significant relationship between SOC and level of income. 
Hypothesis 2: There is a positive and statistically significant relationship between SOC and financial well-being.

Hypothesis 3: Level of income moderates the relationship between SOC and financial wellbeing.

\subsection{Research data}

Secondary data from a nationwide, cross-sectional online employee-wellness survey were obtained from a financial-wellness consulting firm. The data set included participant responses in respect of the following:

(i) demographic variables, including age, gender, population group, marital status, whether the employee was a sole or dual earner (nominal responses), number of dependants, and work performance (ordinal responses);

(ii) the objective financial variable indicating the income level of employees (ordinal responses);

(iii) subjective financial indicators indicating employee perceptions of debt manageability, attitude to retirement, and financial planning (ordinal responses); and

(iv) SOC as measured on a seven-point Likert rating scale (refer to Section 3.3 for a discussion on the SOC measure).

\subsection{Sample}

Of the 10186 employees who received e-invites to participate in the survey, 7185 returned complete and useable questionnaires, representing a 71 per cent response rate. As is evident from the summarised sample characteristics in Table 1 , the 26 to 35 age group had the highest representation (42 per cent), followed by the 36 to 55 age group ( 27 per cent). The sample comprised mostly female ( 66 per cent) participants. Race was represented by 34 per cent black, 18 per cent coloured, 11 per cent Indian and 37 per cent white participants across all working ages and income levels. Dual-income earners made up 54 per cent of the sample, and most participants (27 per cent) fell in the R10 001 to R15 000 income group. Of the sample, many (47 per cent) indicated that their level of performance had improved or stayed unchanged (43 per cent).

Table 1

Sample characteristics and SOC distribution ( $n=7$ 185)

\begin{tabular}{|l|c|c|c|}
\hline \multicolumn{1}{|c|}{ Demographic property } & Category & Frequency & $\%$ \\
\hline Age & $<25$ & 684 & 10 \\
missing $=3$ & $26-35$ & 3018 & 42 \\
& $36-45$ & 1919 & 27 \\
& $46-55$ & 1099 & 15 \\
\hline Gender & $56+$ & 462 & 6 \\
\hline missing $=16$ & Male & 2433 & 34 \\
\hline Population group & Female & 4736 & 66 \\
missing $=7$ & Black & 2428 & 34 \\
& Coloured & 1257 & 18 \\
& Indian & 823 & 11 \\
\hline Single earner & White & 2670 & 37 \\
missing $=5$ & Yes & 3268 & 46 \\
\hline Net monthly & No & 3912 & 54 \\
income & $<$ R5 000 & 439 & 6 \\
missing $=236$ & R5 001-R10 000 & 2088 & 30 \\
& R10 001-R15 000 & 1737 & 25 \\
& R15 001-R20 000 & 1020 & 15 \\
& R20 001-R30 000 & 925 & 13 \\
& R30 001+ & 740 & 11 \\
\hline Work performance & Improved & 3254 & 47 \\
missing =238 & Unchanged & 3029 & 43 \\
& Deteriorated & 664 & 10 \\
\hline
\end{tabular}




\subsection{Measures of SOC, and financial indicators and their respective frequency distributions}

\subsubsection{SOC measure}

The financial-wellness consulting firm decided to use a shortened version of the SOC in order to shorten the survey. It expected that respondents would be less motivated to complete the survey the longer it became. A six-item SOC measure, the Orientation to Life Questionnaire (OLQ-6), was therefore chosen. The OLQ-6 includes Items 8 and 28 (meaningfulness), 12 and 19 (comprehensibility), as well as 9 and 29 (manageability) from Antonovsky's original OLQ-29. The response scale is a seven-point Likert perception rating scale. The OLQ-6 was originally derived by Van Schalkwyk and Rothmann (2008) from structural equation modelling (SEM) with goodness-of-fit statistics $\left(\chi^{2}=3.95 ; d f=8\right.$; IFI $=0.97$; CFI $=0.97$; RMSEA $\left.=0.06\right)$ and highreliability indexes $(\alpha=0,72$ and $\mathrm{r}=0.93)$ for a single-factor model SOC.

In the present study, the internal consistency reliability of the OLQ-6 measure was verified in a scale reliability test with a standardised Cronbach alpha value of 0.86 . A measure of SOC per participant could therefore be calculated as the mean rating response to the six OLQ-6 questions. In addition, the participant SOC scores were categorised as low, medium or high SOC, depending on whether a score fell one standard deviation below the SOC mean score $(4.7-1.45=3.3)$; or within one standard deviation of the SOC mean score $(4.7 \pm 1.45:>3.3$ and $<6.2)$; or one standard deviation above the SOC mean score $(4.7+1.45:>6.2)$. The SOC frequency distribution is reported in Table 2, which indicates that 68 per cent of the respondents reported a moderate SOC.

\subsubsection{Level of income and a financial well-being index measure}

As mentioned, the financial well-being data extracted from the secondary data source included (i) an objective level-of-income variable (choice between six income-bracket options) and (ii) three subjective, self-report financial well-being indicators, namely debt manageability, planning towards retirement, and financial-planning behaviour (choice between three sets of option choices - see Table 2), that were used to derive a financial well-being index (FWB index). The FWB index was calculated as the weighted sum of the three indicators mentioned, following the argument by Cox et al. (2009) that financial health is predicted for people who do proactive financial planning and have manageable debt. Owing to its ordinal form and its value in describing the sample distribution, the frequency distribution of level of income is indicated in Table 1.

The FWB index calculation was implemented as follows: Depending on the response options in respect of the three questions representing a very positive or positive contribution to personal financial well-being, participants' FWB indices were calculated by adding 2 (e.g. "no debt", "save more than minimum in retirement fund", and "have a clear financial plan") or 1 (e.g. "manageable debt" and "focus on saving once debt is repaid") to the base value of 6.0 of the FWB index. A negative value of -1 was added for negative response indicators (e.g. "struggle to pay monthly instalments", "no monthly cash surplus to save", and "have financial goals in place but lack expertise") and -2 for extremely negative response choices (e.g. "cannot afford to pay debt instalments", "I'm not doing anything towards retirement", and "no clear financial direction"). Based on this calculation, individuals' FWB index scores varied between 1 and 12. The FWB index was then categorised into three categories taking into account the mean FWB and its standard deviation range: "unhealthy financial well-being" (category range: < 5); "moderate financial well-being" (category range: 5-8); and "healthy financial well-being" (category range: > 8 ). Table 2 reports the frequency distribution of the FWB index for the extracted data. Prior to the calculation of the FWB index, internal consistency reliability of the FWB construct for the extracted data was verified with a standardised Cronbach alpha value of 0.70 . 
Table 2

$\mathrm{SOC}$ and financial well-being: Descriptive statistics

\begin{tabular}{|c|c|c|c|}
\hline & Category & Frequency & $\%$ \\
\hline \multicolumn{4}{|c|}{$\begin{array}{l}\text { SOC groupings } \\
\text { Mean }=4.7 ; \text { std dev. }=1.45\end{array}$} \\
\hline missing $=722$ & $\begin{array}{l}\text { Low SOC }<3.3 \\
\text { Moderate SOC } \\
\text { High SOC }>6.2\end{array}$ & $\begin{array}{r}1101 \\
4417 \\
945\end{array}$ & $\begin{array}{l}17 \\
68 \\
15\end{array}$ \\
\hline \multicolumn{4}{|c|}{ Financial well-being variables } \\
\hline $\begin{array}{l}\text { Debt status } \\
\text { missing }=497\end{array}$ & $\begin{array}{l}\text { No debt } \\
\text { Manageable debt } \\
\text { Struggle to pay monthly debt } \\
\text { Cannot afford to pay debt }\end{array}$ & $\begin{array}{r}545 \\
3696 \\
1917 \\
530\end{array}$ & $\begin{array}{r}8 \\
55 \\
29 \\
8\end{array}$ \\
\hline $\begin{array}{l}\text { Retirement planning } \\
\text { missing }=542\end{array}$ & $\begin{array}{l}\text { Save > minimum retirement premium } \\
\text { Focus on saving; debt repaid } \\
\text { No saving; no surplus } \\
\text { I am not doing anything }\end{array}$ & $\begin{array}{r}2402 \\
2065 \\
1637 \\
539\end{array}$ & $\begin{array}{r}36 \\
31 \\
25 \\
8\end{array}$ \\
\hline $\begin{array}{l}\text { Financial planning } \\
\text { missing }=498\end{array}$ & $\begin{array}{l}\text { Have clear financial plan } \\
\text { Goals but no expertise } \\
\text { No clear financial direction }\end{array}$ & $\begin{array}{l}2401 \\
3284 \\
1002\end{array}$ & $\begin{array}{l}36 \\
49 \\
15\end{array}$ \\
\hline \multicolumn{4}{|c|}{ Financial well-being (FWB) index } \\
\hline & $\begin{array}{l}\text { Unhealthy FWB: }<5 \\
\text { Moderate FWB: } 5-8 \\
\text { Healthy FWB: }>8\end{array}$ & $\begin{array}{l}1491 \\
2143 \\
3551\end{array}$ & $\begin{array}{l}21 \\
30 \\
49\end{array}$ \\
\hline
\end{tabular}

\subsection{Data analysis}

With the demographic, income, financial well-being and SOC variables defined and the reliability of the relevant measures verified, more advanced analyses were conducted to investigate the relationship dynamics among the study variables. Analyses included:

(i) a multivariate analysis of variance (using the GLM step-wise regression approach to ensure a best-fit model) on the SOC variable as dependent variable, and income, FWB index and demographic variables as explanatory variables;

(ii) Bonferroni multiple comparisons of means tests on the SOC categories of each effect that proved to be statistically significant; and

(iii) Cross reference frequency tables (with associated Pearson's chi-square and CochranArmitage trend test results) of high and low SOC levels against high and low income levels and FWB index categories to further detail the dynamic relationships between SOC, income level and financial well-being.

\section{Results}

\subsection{Analysis-of-variance results}

Considerations that had to be accommodated in the multivariate analysis of variance were: (i) the unequal numbers of respondents per category for some demographic variables; (ii) the selection of a model of best fit; and (iii) the possibility of introducing multicollinearity into the model (e.g. where demographic variables are highly correlated). By following a general linear model (GLM) step-wise regression approach (Proc GLMSELECT of the SAS version 9.4 software package) to the analysis of variance, these considerations were addressed.

In an initial step-wise regression analysis on the SOC scores, level of income, the FWB index, and the demographic variables of age, gender, population group, marital status, sole-/dual-earner status, number of dependants and work performance were included as explanatory variables. The 
fifth step of the analysis identified level of income, the FWB index, work performance (WP), age and earner as effects of the best-fit model. The analysis-of-variance table of these effects and their interaction effects are reported in Table 3, and measures of effect size, namely eta-squared and partial eta-squared, are indicated.

Table 3

ANOVA of best-fit model with effect sizes

\begin{tabular}{|c|c|c|c|c|c|c|c|}
\hline Source & DF & $\begin{array}{l}\text { Sum of } \\
\text { squares }\end{array}$ & $\begin{array}{l}\text { Mean } \\
\text { square }\end{array}$ & F value & $\operatorname{Pr}>\mathrm{F}$ & $\eta^{2}$ & $\eta_{p a r}^{2}$ \\
\hline Model & 43 & 3234.20 & 75.21 & 47.05 & $<.0001$ & 0.241 & 0.249 \\
\hline income & 5 & 255.58 & 51.12 & 31.98 & $<.0001$ & 0.019 & 0.025 \\
\hline FWB index & 2 & 469.32 & 234.66 & 146.81 & $<.0001$ & 0.035 & 0.045 \\
\hline WP & 2 & 346.74 & 173.37 & 108.46 & $<.0001$ & 0.028 & 0.033 \\
\hline earner & 1 & 14.02 & 14.02 & 8.77 & 0.0031 & 0.001 & 0.001 \\
\hline FWB index ${ }^{*}$ WP & 4 & 6.21 & 1.55 & 0.97 & 0.4214 & 0.000 & 0.001 \\
\hline income ${ }^{*} F W B$ index & 10 & 13.02 & 1.30 & 0.81 & 0.6149 & 0.001 & 0.001 \\
\hline income*WP & 10 & 20.59 & 2.06 & 1.29 & 0.2308 & 0.002 & 0.002 \\
\hline income*earner & 5 & 7.41 & 1.48 & 0.93 & 0.4622 & 0.001 & 0.001 \\
\hline FWB index*earner & 2 & 4.04 & 2.02 & 1.26 & 0.2827 & 0.000 & 0.000 \\
\hline WP*earner & 2 & 11.31 & 5.65 & 3.54 & 0.0292 & 0.001 & 0.001 \\
\hline Error & 6376 & 10191.71 & 1.60 & & & & \\
\hline Corrected total & 6419 & 13425.92 & & & & & \\
\hline \multicolumn{8}{|c|}{ R-square $=0.25 ;$ SOC mean $=4.70 ;$ missing $=733$} \\
\hline
\end{tabular}

Results indicate a highly significant general $\mathrm{F}$ statistic of the model $(\mathrm{F}=47.05)$, confirming that further results reported in the table could be considered reliable and not due to chance. The results furthermore show that income, FWB index, WP, earner, and the interaction effect of WP and earner featured as statistically significant effects on SOC (the respective F statistics of 31.98, $146.81,108.46,8.77$ and 3.54 were indicated as statistically significant on the 0.1 per cent, 0.1 per cent, 0.1 per cent, 1 per cent and 5 per cent levels, respectively). This model explains 25 per cent of the variability in the SOC data $(\mathrm{R}$-square $=0.25)$. The partial eta-squared effect-size measure further indicates that the effects of income, FWB index and WP account for 3 per cent, 5 per cent and 3 per cent of the variation in the SOC data, respectively. The nature of the effect of income, FWB index and WP on SOC is further explained in the tables of means calculated in the Bonferroni multiple comparisons of means tests reported in Table 4. The effect of earner status as well as the interaction effect of WP and earner, although indicated as statistically significant, report a partial eta-squared value of 0.001 , which represents very small/negligible effects that were therefore not further explored.

Table 4

Bonferroni multiple comparisons of means test results indicated for each test

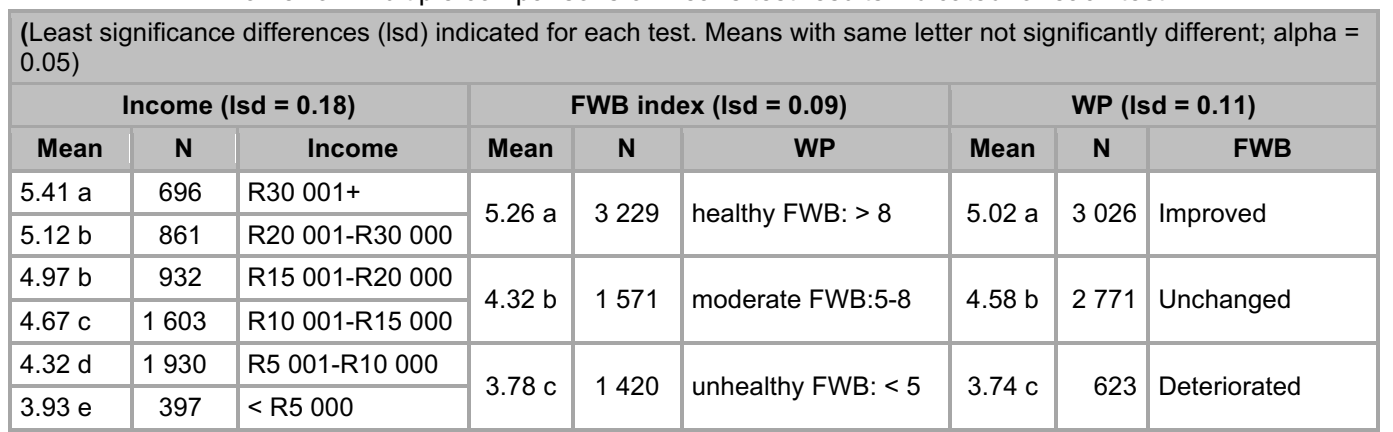


The SOC score means explained in Section 3.3 (low $\mathrm{SOC}<3.3$; medium $\mathrm{SOC}>3.3$ and $<6.2$; high SOC $>6.2$ ) clarifies the nature of the reported significant differences in category means (Bonferroni multiple comparisons of means tests) in Table 4. The SOC means for income categories indicate, for example, that, for the low-income group ( $<$ R5 000), an SOC value of 3.93 indicates a medium (yet lower) SOC, as opposed to the statistically significantly different SOC mean values of 4.97 and 5.12 (indicating a stronger medium SOC) for the R15 000 to R20 000 and R20 001 to R30 000 groups. Following the same tendency, a higher medium SOC applies to the income group of R30 001+ (SOC mean score 5.41). Although the SOC scores therefore range within the medium band of interpretation, the SOC mean scores increase per level of income category and differ statistically significantly across levels of income.

The SOC means for FWB categories reveal that an unhealthy FWB index reports a 3.78 SOC mean score, whereas a healthy FWB index reports a stronger SOC (SOC mean of 5.26). The same SOC trend is reported over the increasingly positive levels of WP: higher SOC mean scores coincide with improved levels of WP. It seems that respondents with a higher SOC report an improvement in their work performance, as opposed to a deteriorated performance reported by those presenting with a lower SOC. However, owing to the primary focus of the study on level of income, financial well-being and SOC, only the suggested tendency for increased levels of income and increased level of FWB index to be associated with increasingly higher levels of SOC (Table 4) is verified in the next section by means of Cochran-Armitage trend tests that were conducted on cross reference frequency tables.

\subsection{Verification of SOC income and SOC-FWB index trends: Cross reference frequency analysis}

The Bonferroni multiple comparisons of means test discussed in Section 4.1 not only assisted in establishing significant mean SOC differences for high- and low-income groups (amongst other differences) and for healthy to unhealthy FWB index levels, but also suggested a trend in SOC increasing over the category levels of income and financial well-being. Therefore, to further detail the dynamics of these effects on SOC and to verify the suggested SOC trends, cross reference frequency tables (Table 5) were calculated on low $(<3.2)$ and high $(>6.2)$ SOC scores over (i) the combined FWB index levels and low- and high-income levels ( $<$ R10 000 and $>$ R20 001), and (ii) the combination of high- and low income-levels and the ordinal option levels of the individual financial well-being indicators (i.e. self-reported debt manageability levels, retirement-planning levels or financial-planning levels). The ordinal property of the income and financial well-being data allows for Cochran-Armitage trend tests to be used to verify (or negate) statistically significant SOC trends over the income-financial well-being combinations.

For low-income and high-income groups $(<\mathrm{R} 10000$ and $>$ R20 001), Table 5 reports eight sets of low and high SOC frequency response patterns for the FWB index levels, debt manageability levels, retirement-planning levels and financial-planning levels. The Cochran-Armitage trend tests reported for each SOC response pattern in Table 5 are all reported to be statistically significant on at least the 0.1 per cent level of significance. Statistical significance in these instances verifies a SOC trend over the levels of, respectively, FWB index, debt manageability, retirement-planning and financial-planning levels (for high- and low-income groups). There is a statistically significant trend for SOC levels to increase as FWB-index-levels increase and for SOC levels to decrease as FWB-index-levels decrease.

With regard to the FWB index for both the lower- and higher-income groups, the same trend is observed: a healthy FWB index corresponds to a high level of SOC (62 per cent for the $<$ R10 000 income group and 89 per cent for the $>$ R20 001 income group), and an unhealthy FWB index corresponds to a low SOC (93 per cent for the $<$ R10 000 income group and 81 per cent for the $>$ R20 001 income group). Analysis of each FWB indicator's behavioural categories reveals more specific trends. For the lower-income group $(<\mathrm{R} 10000)$, respondents with a low SOC tend to favour less healthy means of addressing retirement, such as: "no saving, have debt" (73 per cent as 
opposed to 27 per cent with a higher SOC); "no surplus cash for retirement saving" (83 per cent as opposed to 17 per cent for the higher SOC group); and "I'm not doing anything" (80 per cent as opposed to the 20 per cent of the higher SOC group). Low SOC respondents in the lower-income category struggle to handle debt (84 per cent as opposed to 16 per cent in the high SOC group) and cannot pay their monthly debt instalments (95 per cent as opposed to 5 per cent in the high SOC group). Low SOC in the low-income group also shows "no clear financial direction" (92.3 per cent), with 7.7 per cent of their high SOC counterparts demonstrating the same.

Table 5

Cross-referencing frequency tables

\begin{tabular}{|c|c|c|c|c|c|c|}
\hline \multicolumn{7}{|c|}{$\begin{array}{c}\text { Distribution of high and low SOC scores over FWB index levels for low-income groups }(<R 10000) \& \\
\text { high-income groups (> R20 001) }\end{array}$} \\
\hline \multicolumn{4}{|c|}{ Income $<$ R10 000} & \multicolumn{3}{|c|}{ Income > R20 001} \\
\hline FWB index & $\begin{array}{l}\text { low SOC } \\
(<3.2)\end{array}$ & $\underset{(>6.2)}{\text { high SOC }}$ & Total & low SOC $(<3.2)$ & $\underset{(>6.2)}{\operatorname{high} \text { SOC }}$ & Total \\
\hline $\begin{array}{l}\text { unhealthy } \\
(\mathrm{FWB}<5)\end{array}$ & $\begin{array}{l}285 \\
92.83\end{array}$ & 22 & 307 & $\begin{array}{l}26 \\
81.25\end{array}$ & $\begin{array}{c}6 \\
18.75\end{array}$ & 32 \\
\hline $\begin{array}{l}\text { moderate } \\
\text { (FWB 5-8) }\end{array}$ & $\begin{array}{l}258 \\
82.43\end{array}$ & $\begin{array}{l}55 \\
17.57\end{array}$ & 313 & $\begin{array}{l}27 \\
48.21\end{array}$ & $\begin{array}{l}29 \\
51.79\end{array}$ & 56 \\
\hline $\begin{array}{l}\text { healthy } \\
(\mathrm{FWB}>8)\end{array}$ & $\begin{array}{l}110 \\
37.67\end{array}$ & $\begin{array}{c}182 \\
62.33 \\
\end{array}$ & 292 & $\begin{array}{l}34 \\
10.93 \\
\end{array}$ & $\begin{array}{l}277 \\
89.07\end{array}$ & 311 \\
\hline Total & 653 & 259 & 912 & 87 & 312 & 399 \\
\hline \multicolumn{4}{|c|}{$\begin{array}{l}\text { Exact probability (chi-square statistic }=251.43)<0.0001^{* * *} \\
\text { Probability }(\text { Cochran-Armitage statistic }=-13.94)<0.0001^{* * *}\end{array}$} & \multicolumn{3}{|c|}{$\begin{array}{l}\text { Exact probability }(\text { chi-square statistic }=110.79)< \\
0.0001^{\star \star \star} \\
\text { Probability }(\text { Cochran-Armitage statistic }=-10.47) \\
<0.0001^{\star \star \star}\end{array}$} \\
\hline \multicolumn{7}{|c|}{ Distribution of high and low SOC scor } \\
\hline \multicolumn{4}{|c|}{ Income $<$ R10 000} & \multicolumn{3}{|c|}{ Income > R20 001} \\
\hline Debt management & $\begin{array}{l}\text { low SOC } \\
(<3.2)\end{array}$ & $\begin{array}{l}\text { high SOC } \\
(>6.2)\end{array}$ & Total & $\begin{array}{l}\text { low SOC } \\
(<3.2)\end{array}$ & $\begin{array}{l}\text { high SOC } \\
(>6.2)\end{array}$ & Total \\
\hline No debt & $\begin{array}{l}30 \\
55.56\end{array}$ & $\begin{array}{l}24 \\
44.44\end{array}$ & 54 & $\begin{array}{l}13 \\
20.31\end{array}$ & $\begin{array}{l}51 \\
79.69\end{array}$ & 64 \\
\hline Manageable debt & $\begin{array}{l}185 \\
51.68\end{array}$ & $\begin{array}{l}173 \\
48.32\end{array}$ & 358 & $\begin{array}{l}39 \\
14.13\end{array}$ & $\begin{array}{l}237 \\
85.87\end{array}$ & 276 \\
\hline Struggle to handle debt & $\begin{array}{l}296 \\
84.33\end{array}$ & $\begin{array}{l}55 \\
15.67\end{array}$ & 351 & $\begin{array}{l}24 \\
50.00\end{array}$ & $\begin{array}{l}24 \\
50.00\end{array}$ & 48 \\
\hline $\begin{array}{l}\text { Cannot pay monthly } \\
\text { instalments }\end{array}$ & $\begin{array}{c}142 \\
95.30\end{array}$ & $\begin{array}{l}7 \\
4.70 \\
\end{array}$ & 149 & $\begin{array}{c}11 \\
100.00\end{array}$ & $\begin{array}{l}0 \\
0.00\end{array}$ & 11 \\
\hline Total & 653 & 259 & 912 & 87 & 312 & 399 \\
\hline \multicolumn{4}{|c|}{$\begin{array}{l}\text { Probability }(\text { chi-square statistic }=145.87)<0.001^{* \star *} \\
\text { Probability }(\text { Cochran-Armitage statistic }=11.10)<0.001^{\star \star *}\end{array}$} & \multicolumn{3}{|c|}{$\begin{array}{l}\text { Exact probability }(\text { chi-square statistic }=71.45)< \\
0.0001^{\star \star \star} \\
\text { Probability }(\text { Cochran-Armitage statistic }=6.15)< \\
0.0001^{\star \star \star}\end{array}$} \\
\hline \multicolumn{7}{|c|}{$\begin{array}{r}\begin{array}{r}\text { Distribution of high and low SOC scores over retirem } \\
\text { high-income } \mathrm{g}\end{array}\end{array}$} \\
\hline 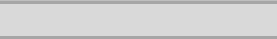 & \multicolumn{3}{|c|}{ Income $<$ R10 000} & \multicolumn{3}{|c|}{ Income > R20 001} \\
\hline Retirement planning & $\begin{array}{c}\text { low SOC } \\
(<3.2)\end{array}$ & $\underset{(>6.2)}{\text { high SOC }}$ & Total & $\begin{array}{l}\text { low SOC } \\
(<3.2)\end{array}$ & $\underset{(>6.2)}{\operatorname{high} \text { SOC }}$ & Total \\
\hline Save once debt repaid & $\begin{array}{l}242 \\
72.67\end{array}$ & $\begin{array}{l}91 \\
27.33\end{array}$ & 333 & $\begin{array}{l}24 \\
32.88\end{array}$ & $\begin{array}{l}49 \\
67.12\end{array}$ & 73 \\
\hline No monthly surplus cash & $\begin{array}{l}257 \\
82.64\end{array}$ & $\begin{array}{l}54 \\
17.36 \\
\end{array}$ & 311 & $\begin{array}{l}24 \\
58.54 \\
\end{array}$ & $\begin{array}{l}17 \\
41.46\end{array}$ & 41 \\
\hline $\begin{array}{l}\text { Save more than minimum } \\
\text { premium }\end{array}$ & $\begin{array}{l}65 \\
41.40\end{array}$ & $\begin{array}{l}92 \\
58.60\end{array}$ & 157 & $\begin{array}{l}25 \\
9.58\end{array}$ & $\begin{array}{l}236 \\
90.42\end{array}$ & 261 \\
\hline I am not doing anything & $\begin{array}{l}84 \\
80.00\end{array}$ & $\begin{array}{l}21 \\
20.00\end{array}$ & 105 & $\begin{array}{l}11 \\
52.38\end{array}$ & $\begin{array}{l}10 \\
47.62\end{array}$ & 21 \\
\hline Total & 648 & 258 & 906 & 84 & 312 & 396 \\
\hline \multicolumn{4}{|c|}{$\begin{array}{l}\text { Exact probability (chi-square statistic }=92.72)<0.0001^{* * *} \\
\text { Probability }(\text { Cochran-Armitage statistic }=-3.74)<0.0001^{\star \star *}\end{array}$} & \multicolumn{3}{|c|}{$\begin{array}{l}\text { Exact probability }(\text { chi-square statistic }=73.46)< \\
0.0001^{\star \star \star} \\
\text { Probability }(\text { Cochran-Armitage statistic }=-4.87)< \\
0.0001^{\star \star \star}\end{array}$} \\
\hline
\end{tabular}




\begin{tabular}{|c|c|c|c|c|c|c|}
\hline \multicolumn{7}{|c|}{$\begin{array}{l}\text { Distribution of high and low SOC scores over financial-planning levels for low-income groups (<R10 000) \& } \\
\text { high-income groups (> R20 001) }\end{array}$} \\
\hline \multirow[b]{2}{*}{ Financial planning } & \multicolumn{3}{|c|}{ Income < R10 000} & \multicolumn{3}{|c|}{ Income > R20 001} \\
\hline & $\begin{array}{c}\text { low SOC } \\
(<3.2)\end{array}$ & $\underset{(>6.2)}{\text { high SOC }}$ & Total & $\begin{array}{c}\text { low SOC } \\
(<3.2)\end{array}$ & $\underset{(>6.2)}{\operatorname{high} \text { SOC }}$ & Total \\
\hline Do financial planning & $\begin{array}{l}53 \\
25.12\end{array}$ & $\begin{array}{l}158 \\
74.88\end{array}$ & 211 & $\begin{array}{l}18 \\
7.44\end{array}$ & $\begin{array}{l}224 \\
92.56\end{array}$ & 242 \\
\hline $\begin{array}{l}\text { Have aspirations but ignorant } \\
\text { of how to realise plans }\end{array}$ & $\begin{array}{c}395 \\
82.46\end{array}$ & $\begin{array}{l}84 \\
17.54\end{array}$ & 479 & $\begin{array}{l}43 \\
35.25\end{array}$ & $\begin{array}{l}79 \\
64.75\end{array}$ & 122 \\
\hline No clear financial direction & $\begin{array}{l}204 \\
92.30\end{array}$ & $\begin{array}{l}17 \\
7.70\end{array}$ & 221 & $\begin{array}{l}26 \\
74.29\end{array}$ & $\begin{array}{c}9 \\
25.71\end{array}$ & 35 \\
\hline Total & $\begin{array}{l}652 \\
71.57\end{array}$ & $\begin{array}{l}259 \\
28.43\end{array}$ & 911 & $\begin{array}{l}87 \\
21.81\end{array}$ & $\begin{array}{l}312 \\
78.19\end{array}$ & 399 \\
\hline \multicolumn{4}{|c|}{$\begin{array}{l}\text { Probability (chi square statistic }=298.40)<0.001^{* \star *} \\
\text { Probability }(\text { Cochran-Armitage statistic }=15.34)<0.001^{* \star *}\end{array}$} & \multicolumn{3}{|c|}{$\begin{array}{l}\text { Exact probability }(\text { chi-square statistic }=89.76) \\
<0.0001^{* \star *} \\
\text { Probability }(\text { Cochran-Armitage statistic }=9.88)< \\
0.0001^{* \star *}\end{array}$} \\
\hline \multicolumn{4}{|l|}{ Frequency missing $=415$} & \multicolumn{3}{|c|}{ Frequency missing $=99$} \\
\hline
\end{tabular}

In the higher-income group ( $>$ R20 001), the higher SOC group tends to favour more healthy retirement options such as "saving more than the minimum required premium" (90 per cent as opposed to the 10 per cent of the lower SOC group). They report manageable debt (86 per cent as opposed to 14 per cent in the low SOC group) or even no debt (80 per cent as opposed to 20 per cent of the low SOC group) and do financial planning (92.45 per cent) more than the low SOC group (7.44 per cent). Generally, in terms of debt manageability, retirement planning and financial planning for lower-income groups, the subgroup with a high SOC proportionately demonstrates a healthier perspective with regard to managing their debt, planning for their retirement and their general financial planning than the lower SOC subgroup. The same trend applies to the highincome group (> R20 001).

\section{Discussion}

The aim of this study was to examine the relationship dynamics between level of income, financial well-being and SOC. In addition, the study investigated the effect of various demographic variables on SOC. Analysis-of-variance results and trend tests indicate that level of income relates positively to SOC, supporting a basic tenet of the Easterlin Paradox, namely that psychological well-being relates to wealth. Results further demonstrate a significant difference in mean SOC for varying levels of financial well-being, indicating a positive relationship between SOC and financial well-being. Whereas Hypotheses 1 and 2 are accepted, Hypothesis 3 is rejected, as results show that, irrespective of level of income, SOC relates positively to financial well-being. Analysis-of-variance results do not indicate a significant interaction effect for level of income and financial well-being on SOC. In the cross reference frequency analysis, both high- and low-income groups with low SOC presented with significantly more self-perceived debt challenges and less constructive retirement- and financial-planning behaviour than those with high SOC in each income group. It seems that even high-income, low SOC individuals present with more debt difficulties and poor financial planning than high-income, high SOC individuals (with a similar trend in the low-income groups).

These findings have significant value for understanding financial well-being behaviour in the organisation and show that one cannot assume that higher-income employees will by default of their income level experience higher levels of financial well-being or make better financial decisions. Psychological well-being, and specifically SOC, could play an important role in distinguishing financial well-being and potentially provides a development perspective to enhance constructive financial decision making and behaviour. Employees with low SOC present a potential risk to the organisation, bearing in mind the potential risks of financially unhealthy employees in the workplace. The lower the income category of the employee, the higher the risk of unhealthy financial behaviour if also coupled with low SOC. However, low-income employees, if 
presenting with high SOC, may also have a better chance to present with financial well-being. According to Leary (2009), employers are uniquely positioned to provide crucial financialplanning assistance for employees, since organisations benefit from employing financially well employees. Having an indication of employees' SOC as a potential indicator of risk of dysfunctional financial behaviour may assist organisations to identify low-risk employees in order to develop and assist them proactively in their financial behaviour. Salutogenic development interventions will also indirectly facilitate financial well-being, and the present study suggests that organisations should not only rely on financial literacy and economic skills development, but that these strategies should also be accompanied by investment in the concurrent development of employees' psychological well-being.

\section{Limitations and recommendations}

The cross-sectional, secondary data design applied in the present study has several limitations that should be considered when interpreting the results and should be taken into account in future research. First, the short-version, one-factor model SOC measure, OLQ-6, was used, potentially restricting relationship trends. However, the size of the wellness survey and pragmatic considerations in terms of ensuring good response rates with little effort and time needed to complete the survey, originally directed project decisions. The OLQ-6 has also demonstrated good reliability in this study, as in the Van Schalkwyk and Rothmann (2008) study, and was deemed appropriate. Second, in having to rely on the financial well-being questionnaire included in the survey, the researcher had to apply post hoc value judgements in respect of responses included in the questionnaire in order to derive workable data to include in the analyses. As such, interpretations of high to low SOC, high- and low-income categories and calculations of the FWB index may produce different results when valued differently. In all respects, the researcher attempted to substantiate and explicate value judgements made. Lastly, the study relied on selfreport instruments, which are always subject to scrutiny in terms of social-desirability bias (Ones, Viswesvaran \& Reiss, 1996; Paunonen \& LeBel, 2012). However in well-being research, selfreport measures are predominantly used and deemed acceptable indicators of reality from a constructivist orientation. Self-report measures shed light on the individual's level of affective experience and perception that cannot be derived from objective measures and continue to significantly contribute to our understanding of individual differences (Hodgkinson \& SadlerSmith, 2014).

For further research, different psychological well-being constructs (e.g. locus of control and resilience) can be included in order to provide organisations with evidence-based substantiation to incorporate psychological well-being interventions in proactively addressing potential financial well-being risk in the workforce. Thorough conceptualisation of the financial well-being construct should lead to the design of well-rounded financial well-being measures that could provide more robust data in relation to psychological well-being. The expected employer responsibility in terms of employee wellness continues to escalate (Dickson-Swift, Fox, Marshall, Welch \& Willis, 2014) and the economic challenges individuals have to cope with only become more strenuous every year (Bosman, 2007; De Clercq et al., 2014). Investing in its employees' psychological well-being with a clear indication of the specific well-being constructs to be developed will benefit management in its pursuit of managing a financially healthy workforce.

\section{Acknowledgements}

This work is based on research supported in part by the National Research Foundation (NRF) of South Africa (Unique Grant No. 84412). Any opinion, finding, conclusion or recommendation expressed in this work is that of the author and the NRF accepts no liability in this regard. I also wish to gratefully acknowledge Ms Helene Muller of Unisa's College of Graduate Studies who played an invaluable role in the statistical analysis. 


\section{References}

ANTONOVSKY, A. 1979. Health, stress and coping. San Francisco: Jossey-Bass.

AUSTIN, K. \& CILLIERS, F. 2011. The psychometric relationship between career thinking and salutogenic functioning amongst unemployed adults. SA Journal of Industrial Psychology, 37(1). http://dx.doi.org/10.4102/sajip.v37i1.969 [accessed January 2015].

BARNARD, H.A., PETERS, D. \& MULLER, H. 2010. Financial health and sense of coherence. SA Journal of Human Resource Management, 8(1):1-12.

BASINSKA, M.A., ANDRUSZKIEWICZ, A. \& GRABOWSKA, M. 2011. Nurses' sense of coherence and their work related patterns of behavior. International Journal of Occupational Medicine and Environmental Health, 24(3):256-266.

BELL, M.M., NELSON, J.S., SPANN, S.M., MOLLOY, C.J., BRITT, S.L. \& GOFF, B.S.N. 2014. The impact of financial resources on soldiers' wellbeing. Journal of Financial Counseling \& Planning, 25(1): 41-52.

BERG, M. \& VEENHOVEN, R. 2010. Income inequality and happiness in 119 nations. In B Greve (ed), Social policy and happiness in Europe (174-194). Cheltenham: Edgar Elgar.

BERNABÉ, E., TSAKOS, G., WATT, R.G., SUOMINEN-TAIPALE, A.L., UUTELA, A., VAHTERA, J. \& KIVIMÄKI, M. 2009. Structure of the sense of coherence scale in a nationally representative sample. The Finnish Health 2000 Survey. Quality of Life Research, 18(5):629-636.

BOSMAN, P. 2007. Employee assistance and the new National Credit Act. Professional Accountant, Sept/Oct:334-336.

BOYCE, C.J., BROWN, G.D.A. \& MOORE, S.C. 2010. Money and happiness: Rank of income, not income, affects life satisfaction. Psychological Science, 21(4):471-475.

BOYCE, C.J., WOOD, A.M., BANKS, J., CLARK, A.E. \& BROWN, G.D.A. 2013. Money, well-being, and loss aversion: Does an income loss have a greater effect on well-being than an equivalent income gain? Psychological Science, 24(12):2557-2562.

BROWN, S., TAYLOR, K. \& PRICE, S.W. 2005. Debt and distress: Evaluating the psychological cost of credit. Journal of Economic Psychology, 26:642-663.

BURR, A., SANTO, J. \& PUSHKAR, D. 2011. Affective wellbeing in retirement: The influence of values, money, and health across three years. Journal of Happiness Studies, 12(1):17-40.

COETZEE, S. \& VIVIERS, R. 2007. An overview of research on positive psychology in South Africa. South African Journal of Psychology, 37(3):470-490.

COX, A., HOOKER, H., MARKWICK, C. \& REILLY, P. 2009. Financial wellbeing in the workplace. Research report 464. Sussex: Institute for Employment Studies.

DEATON, A. 2008. Income, health, and wellbeing around the world: Evidence from the Gallup World Poll. Journal of Economic Perspectives, 22:53-72.

DE CLERCQ, B., MEIRING, J., VAN AARDT, C.J. \& VAN TONDER, J.A. 2014. South African Household Financial Wellness Index 2014. https://www.momentum.co.za/for/you/sponsorships/ householdfinancial-wellness-index [accessed January 2015].

DELAFROOZ, N. \& PAIM, L.H. 2011. Determinants of financial wellness among Malaysia workers. African Journal of Business Management, 5(24):10092-10100.

DICKSON-SWIFT, V., FOX, C., MARSHALL, K., WELCH, N. \& WILLIS, J. 2014. What really improves employee health and wellbeing? International Journal of Workplace Health Management, 7(3):138-155. doi.org/10.1108/IJWHM-10-2012-0026.

DIENER, E., HARTER, N.G. \& ARORA, R. 2010. Wealth and happiness across the world: Material prosperity predicts life evaluation, whereas psychosocial prosperity predicts positive feelings. Journal of Personality and Social Psychology, 99:52-61.

DIENER, E. \& SELIGMAN, M.E.P. 2004. Beyond money: Toward an economy of wellbeing. Psychological Science in the Public Interest, 5(1):1-31.

DIENER, E., TAY, L. \& OISHI, S. 2013. Rising income and the subjective wellbeing of nations. Journal of Personality and Social Psychology, 104(2):267-276. 
DOLAN, P., PEASGOOD, T. \& WHITE, M. 2008. Do we really know what makes us happy? A review of the economic literature on the factors associated with subjective wellbeing. Journal of Economic Psychology, 29:94-122.

EASTERLIN, R.A. 1947. Does Economic Growth Improve the Human Lot? Some empirical evidence. In PA David \& MW Reder (eds.) Nations and households in economic growth: Essays in honor of Moses Abramovitz (89-125). New York: Academic Press.

EASTERLIN, R.A. 2001. Income and happiness: Towards a unified theory. The Economic Journal, 111: 465-484.

EASTERLIN, R.A., MCVEY, L.A., SWITEK, M., SAWANGFA, O. \& ZWEIG, J. 2010. The happinessincome paradox revisited. Proceedings of the National Academy of Science, 107(52):22463-22468.

FELDT, T., LESKINEN, E., KOSKENVUO, M., SUOMINEN, S., VAHTERA, J. \& KIVIMÄKI, M. 2011. Development of sense of coherence in adulthood: A person-centred approach. The population-based HeSSup cohort study. Quality of Life Research, 20:69-79.

FIELD, L.K. \& BUITENDACH, J.H. 2011. Happiness, work engagement and organisational commitment of support staff at a tertiary education institution in South Africa. SA Journal of Industrial Psychology, 37(1). http://dx.doi.org/10.4102/sajip.v37i1.946 [accessed January 2015].

FITCH, C., HAMILTON, S., BASSETT, P. \& DAVEY, R. 2011. The relationship between personal debt and mental health: A systematic review. Mental Health Review Journal, 16(4):153-166.

GARDARSDÓTTIR, R.B., DITTMAR, H. \& ASPINALL, C. 2009. It's not the money, it's the quest for a happier self: The role of happiness and success motives in the link between financial goals and subjective wellbeing. Journal of Social \& Clinical Psychology, 28(9):1100-1127.

GERRANS, P., SPEELMAN, C. \& CAMPITELLI, G. 2014. The relationship between personal financial wellness and financial wellbeing: A structural equation modeling approach. Journal of Family and Economic Issues, 35:145-160.

GROPP, L., GELDENHUYS, D. \& VISSER, D. 2007. Psychological wellness constructs: Relationships and group differences. SA Journal of Industrial Psychology, 33(3):24-34.

HODGKINSON, G.P. \& SADLER-SMITH, E. 2014. Self-report assessment of individual differences in preferences for analytic and intuitive processing: A critical review. In M. Sinclair (ed.) Handbook of research methods on intuition (101-115). Cheltenham: Edward Elgar.

JOO, S. 2008, Personal financial wellness. In J.J. Xiao (ed), Handbook of consumer finance research (21-33). New York: Springer.

KAHNEMAN, D. \& DEATON, A. 2010. High income improves evaluation of life but not emotional wellbeing. Proceedings of the National Academy of Sciences of the United States of America, 107(38): 16489-16493.

LAYARD, R., CLARK, A., \& SENIK, C. 2012. The causes of happiness and misery. Published in Helliwell, J., Layard, R. \& Sachs. J. (eds.) World happiness report (58-89). New York, NY: United Nations.

LEARY, D. 2009. Take 5 - Tiffany and company's take on financial wellness. Benefits Quarterly, 25(3): 17-19.

LIUKKONEN, V., VIRTANEN, P., VAHTERA, J., SUOMINEN, S., SILLANMÄKI, L. \& KOSKENVUO, M. 2010. Employment trajectories and changes in sense of coherence. European Journal of Public Health, 20(3):293-298.

MULLER, Y. \& ROTHMANN, S. 2009. Sense of coherence and employees' perceptions of helping and restraining factors in an organisation. SA Journal of Industrial Psychology, 35(1):89-98.

O'NEILL, B., SORHAINDO, B., XIAO, J.J. \& GARMAN, E.T. 2005. Financially distressed consumers: Their financial practices, financial well-being, and health. Financial Counseling and Planning, 16(1):73-87.

ONES, D.S., VISWESVARAN, C. \& REISS, A.D. 1996. Role of social desirability in personality testing for personnel selection: The red herring. Journal of Applied Psychology, 81:660-679.

PAUNONEN, S.V. \& LEBEL, E.P. 2012. Socially desirable responding and its elusive effects on the validity of personality assessments. Journal of Personality and Social Psychology, 103(1):158-175.

RUTHERFORD, L.G. \& FOX, W.S. 2010. Financial wellness of young adults. Family and Consumer Sciences Journal, 38(4):468-484. 
SACKS, D.W., WOLFERS, J. \& STEVENSON, B. 2012. The new stylized facts about income and subjective wellbeing. Emotion, 12(6):1181-1187.

SIAHPUSH, M., SPITTAL, M. \& GOPAL, G.K. 2007. Association of smoking cessation with financial stress and material wellbeing: Results from a prospective study of a population-based national survey. American Journal of Public Health, 97(12):2281-2287.

SIEBERHAGEN, C., PIENAAR, J. \& ELS, C. 2011. Management of employee wellness in South Africa: Employer, service provider and union perspectives. SA Journal of Human Resource Management, 9(1). http://dx.doi.org/10.4102/sajhrm.v.9i1.305 [accessed January 2015].

VAN SCHALKWYK, L. \& ROTHMANN, S. 2008. Validation of the orientation to life questionnaire (OLQ) in a chemical factory. SA Journal of Industrial Psychology, 34(2):31-39.

VOGT, K., JENNY, G.J. \& BAUER, G.F. 2013. Comprehensibility, manageability and meaningfulness at work: Construct validity of a scale measuring work-related sense of coherence. SA Journal of Industrial Psychology, 39(1). http:// dx.doi.org/10.4102/sajip. v39i1.1111 [accessed January 2015].

WOLBRING, T., KEUSCHNIGG, M. \& NEGELE, E. 2013. Needs, comparisons, and adaptation: The importance of relative income for life satisfaction. European Sociological Review, 29(1):86-104.

YIN-FAH, B.C., MASUD, J., HAMID, T.A. \& PAIM, L. 2010. Financial wellbeing of older peninsular Malaysians: A gender comparison. Asian Social Science, 6(3):58-71.

ZURLO, K.A., KIM, H. \& YOON, W.A. 2014. Unsecured consumer debt and mental health outcomes in middle-aged and older Americans. Journals of Gerontology, Series B: Psychological Sciences and Social Sciences, 69(3):461-469. 